F. Schanz: Ueber den mechanischen Verschluss des Ductus arteriosus. 239

\title{
Ueber den mechanischen Verschluss des Ductus arteriosus.
}

Von

Dr. med. Fritz Schanz.

Hierzu Tafel IV und V.

Ueber den Verschluss des Ductus arteriosus Botalli ${ }^{1}$ ) bestehen zur Zeit noch sehr verschiedene Ansichten, so dass es sich wohl lohnen dürfte, dieselben einmal zu vergleichen und zu prüfen.

Litteratur: Ch. J. Trew sagt in einer Dissertation: De differentiis inter hominem natum et nascendum 1736: Hiatus foraminis ovalis atque canalis arteriosi clauditur ex mutatione partium eos componentium und zwar der Ductus arteriosus speziell : auctione tunicarum interiora versus, er wendet sich damit gegen Vater, der eine besondere, im Gang abgelagerte, ibn verstopfende Substantia medullaris annimmt. Ebenso hat Haller von geronnenen polypösen Massen gesprochen, die den Gang verschliessen. Kili a n ${ }^{2}$ ) giebt an, dass der grössere Blutandrang nach den Lungen die Ursache sei, die den Verschluss des Ductus arteriosus bedinge. Chevers ${ }^{3}$ ) ist der Ansicht, dass der Nervus recurrens, der sich um den Ductus arteriosus an der Stelle, wo er in die Aorta mündet, herumlegt, beim Einsetzen der Athmung einen Verschluss berbeiführt. Wie schon Virchow bemerkt, ist ein solehes Verhalten mit

1) Ich werde denselben im Weiteren einfach Ductus arteriosus nennen, zumal da Botallius nur das Verdienst hat, ihn wieder entdeckt zu haben, den schon $\mathrm{Galen}$ beschrieben hatte.

2) Kilian, Ueber den Kreislauf des Blutes im Kinde, welches noch nicht geathmet hat. Karlsruhe 1826 .

3) Normann Chevers, Observation on the Permanence of the Ductus Arteriosus and Constriction of the Thoracie Aorta. And on the Meansby which the Duct becomes naturally closed in London. med. Gaz. 1845 Mai u. Gaz. méd. de Paris Nov. 45. 
dem Wesen eines so wichtigen Nerven kaum zu vereinigen. Soviel geht aber aus seiner Arbeit hervor, dass er der Ansicht ist, dass der Verschluss mit den ersten Athemzïgen eintritt, und derselbe aus diesem Grunde wohl nur ein mechanischer sein kann.

Er erwähnt eine Abhandlung von $\mathrm{K}$ ing, der der Ansicht ist, dass die Ausdehnung des linken Bronchus bei Beginn der Respiration ein Zusammendricken des Ductus arteriosus bewirke; ausserdem futhrt er eine Arbeit von Bernt ${ }^{1}$ ) an, in der gesagt wird: Wenn das Kind nur wenige Minuten geathmet hat, zieht sich der Ductus an seinen Enden zusammen, gewöhnlich am Aortenende.

Eine sehr ausführliche Schilderung der Cirkulationsänderungen bei der Geburt giebt $\mathrm{Kiw}$ isch'2). Durch die Ausdehnung der Lungen wird nicht nur die Luft, sondern auch das Blut von denselben angesaugt, dadurch entsteht nothwendiger Weise eine verminderte Strömung nach dem Ductus, welcher, sich dem dïnneren Blutstrahl accommodirend, eine ringförmige Zusammenziehung erleidet. Es findet am Ductus mehrfache anatomische Eigenthtumlichkeiten, die er wie folgt beschreibt: „Seine Wandungen sind durchgebend beträchtlich dicker als die der anstossenden Gefässe, seine Innenfläche zeigt ein eigenthtimliches punktirtes Aussehen, sowie seine mittleren Schichten eine Art cavernöses, leicht verschiebbares Gewebe darbieten. In seiner Muskelhaut sind die Muskelfasern leicht zu isoliren, seine äusseren Schichten reich an Gefässen und Nerven. Hieraus ergiebt sich eine leichte Verschieblichkeit der inneren Haut, welche bei eintretender Contraktion der tieferen Schichten sich in zahlreiche Längenfalten legt, sowie eine bedeutende Schwellbarkeit und Contraktionsfähigkeit der mittleren und äusseren Gefässbaut. Alle diese Umstände vereint begïnstigen nach Abnahme des Blutstromes die Verengung des Canals, demungeachtet wäre hiermit noch nicht gentigent erklärt, warum die kräftigen Contraktionen des rechten Ventrikels - nachdem das Athmen einmal im Gange ist, und die beträchtlicbe Ableitung des Blutstromes bei den ersten A themzuigen sich nicht mehr wiederholt das Blut nicht mit erneuter Kraft wieder in den Ductus treibt und dessen Zusammenziehung tiberwindet."

Hier macht sich Ki w is ch selbst den wesentlichsten Einwurf,

1) Taylor's Manual of Medical Jurisprudence p. 474.

2) Kiwisch, Die Geburtskunde 1851. 
er sucht ihn abel dadurch zu beseitigen, dass er eine eigenthümliche Nerventhätigkeit annimmt, „durch welche sich in dem Ductus eine ebenso lebhafte, dem Blutandrang widerstehende spontane Contraktion einstellt, als antagonistisch eine gleichartige Relaxation in den Lungenarterien wirksam wird."

Die vollständige Schliessung wird auch nach seiner Ansicht durch eine fortschreitende Lockerung und Wucherung seiner inneren Schicht bewirkt, welche endlich eine unmittelbare Beriihrung seiner Wandungen und deren Verwachsung zur Folge hat.

Cruveilhier glaubt, wie ich bei Virchow gefunden habe, dass der Verschluss durch pseudomembranöse Adbäsion, selten durch Pfropfbildung, zuweilen durch beides zu Stande komme.

Rokitansky ${ }^{1}$ ) behandelt die Aneurysmen und das Offenbleiben des Ductus arteriosus, was nach ihm auf anomalen Involutionsvorgängen desselben beruht. Er giebt an, dass die Involution in einem Schrumpfen und Veröden des Ductus in der Regel ohne Vermittlung eines Blutpfropfen besteht, und dass dieser Prozess nicht im ganzen Ductus gleichzeitig vor sich geht; zuerst beginnt er ziemlich in der Mitte, aber etwas mehr nach der Lungenarterie zu, dies bätte auch zur Folge, dass das Lungenarterienostium kleiner ist als das Ostium aorticum. Virchow ${ }^{2}$ ) ist auch der Ansicht, dass die Obliteration des Ductus durch Contraktion seiner Wandung zu Stande komme, dass aber der vollständige Verschluss desselben durch Thrombusbildung erreicht werde.

Die erste auf die Ursachen dieses Verschlusses speziell eingehende Arbeit ist die von Lange ${ }^{3}$ ); er sucht durch mikroskopische Untersuchungen der Struktur des Ductus, sowie der Aorta und der Pulmonalarterie Verschiedenheiten zwischen denselben festzustellen. Er findet am Ductus die nahe der Intima gelegenen longitudinalen Kernstränge vermehrt und die ganze Wandung infolge der mächtigen Kernwucherungen bedeutend dicker als die der Aorta und Pulmonalarterie. Diese Wucherung ertheilt der

1) Ueber einige der wichtigsten Krankheiten der Arterien in: Denkschriften der kais. Academie der Wissenschaften, Math.-naturw. Klasse. Wien 1852. Bd. 4, S. 34 u. 53.

2) Gesammelte Abhandlungen zur wissenschaftlichen Medicin 1856. S. 594 .

3) Langer, Zur Anatomie der fötalen Kreislaufsorgane, in: Zeitschr. der Gesellschaft der Aerzte zu Wien 1857, S. 328. 
Innenfläche des Ganges ein runzliges Ansehen. Elastisches Gewebe kommt nach Langers Ansicht im Ductus gar nicht zur Entwicklung und an seiner Statt ist eine Art umfangreiches Bindegewebe vorbanden. Am 9. Tage aber fand er die innere Oberfläche noch faltiger und die Kernwucherungen besonders in der Mitte vermehrt, so dass der Gang nach Fortnahme seiner vorderen Wand eine Sanduhrform erhält.

Auf ihn bezieht sich die von der Göttinger medizinischen Fakultät gekrönte Preisschrift von Dr. Walkhoff ${ }^{1}$ ). Auch er bestätigt, dass die Struktur des Ductus arteriosus von der der Art. pulmonalis und Aorta bedeutend abweicht.

Er untersucht den Ductus nicht nur in der Mitte, sondern auch seine Uebergangsstellen in die Aorta und Art. pulmonalis. Die Intima des Ductus weicht insofern von der der anderen Gefässe $a b$, als ihre Struktur eine bedeutend lockerere und die Entwickelung des elastischen Gewebes bei weitem hinter der der letzteren zurückgeblieben ist. Diese Erscheinung tritt aber in der nun folgenden Tunica media noch evidenter herver, jene scharf contourirten, dicken, elastischen Faserplatten der Aorta und Art. pulmonalis fehlen hier gänzlich, ebenso die in den Interstitien liegenden glatten Muskelzellen. Jedoch will Walkh off im Gegensatz zu Langer ein zartes, longitudinal verlaufendes, elastisches Netzwerk gefunden haben, welches als dickere Faserbundel aus den benachbarten Arterien übertrat. Zwischen den Maschen dieses Netzwerkes findet er Zellen von exquisit spindelförmigem Charakter, er hält sie für Zellen, die sich, wie in anderen bindegewebigen Organen, zu Bindegewebs-oder elastischen Fasern umbilden.

Die Ursache des Verschlusses glaubt er auch im Wesentlichen in histologisehen Veränderungen der Wand des Ductus suchen zu mussen, neben ihr lässt er aber auch noch 2 Bedingungen mitwirken, die Lageveränderung und die Blutgerinnung. Er sagt wörtlich: „Der innere Thoraxraum ist beim todtgebornen Kinde bekanntlich sehr beschränkt, die Lungen liegen noch im collabirten Zustande dicht an die Wirbelsäule gedrängt, das Zwergfell ragt hoch in die Brusthöhle hinauf, und das Herz hat mehr

1) Walkhoff, Das Gewebe des Ductus arteriosus und die Obliteration derselben: Zeitschrift für rat. Medicin XXXVI, 1869, S. 109. 
eine horizontale Lagerang. Nach eingetretener respiratorischer Thätigkeit ändert sich dies aber vollständig, die Lungen dehnen sich um mehr als das Doppelte aus und abben dadurcb zugleich einen beträchtlichen Zug auf die an ihrer Wurzel eintretenden Pulmonaläste aus, in Folge dessen diese aus ihrem mehr nach hinten gerichteten Verlauf in eine seitliche nacb aussen gewandte Richtung abgelenkt werden, und damit in gleicher Weise eine stärkere Krïmmung resp. Einziehung des Theilungsendes der Art. pulmonalis und des Ansatzpunktes des Ductus, nach hinten $z u$, verursachen, die sich in den ersten 2 bis $3 \mathrm{Tagen} \mathrm{durch}$ eine im kleinen Kreislauf eintretende Druckerhöhung und gleichzeitig hervorgerufene Dehnung und stärkere Entwickelung der Wandung noch vermehren wird. Ausserdem scheint auch die veränderte Herzlage und die aus der stärkeren Muskelaktion des linken Ventrikels resultirende und zunehmende Krümmung der Aorta ascendens nach rechts und aussen einigen Einfluss auf die spätere Lage des Ductus zu haben, da sich diese Theile in dem noch lockeren Bindegewebe leicht verschieben können. Alle diese Momente zusammen genommen rufen also nicht nur eine stärkere Ableitung des durch die Arteria pulmonalis strömenden Blutes in die Lungenäste hervor, sondern sind auch im Stande, unmittelbar an der Theilungsstelle eine Art Knickung des Ganges und zwar in der Weise zu veranlassen, dass er aus dem fruheren, die Verlängerung der genannten Arterie bildenden nach aussen gerichteten Verlauf, in eine nach innen etwas winklige, zu ihrer oberen Wand mehr senkrecht stehende Richtung gebracht wird, in der er steil gegen die Aorta ansteigt und in diese annähernd rechtwinklig einmündet, wie ich dies bei 3 Tage alten Kindern mehrmals beobachtete. Hierdurch werden aber gleichzeitig seine vordere und hintere Wand einander so bedeutend genähert, dass schon am 3. Tag bei Injek. tionsversuchen keine Massen mehr in den Gang eindringen, wozu auch noch der Umstand wesentlich beitragen mag, dass durch eine mit der Vergrösserung der Lungenäste eintretende Ausdehnung der hinteren Wand der Theilungsstelle der Art. pulmonalis sein Anheftungspunkt so an deren vordere innere Wand gedrängt, dass ein von innen wirkender Druck seine untere $W$ and ventilartiggegendie obere andrücken mas." In zweiter 
Linie kommen in Betracht die feineren Aenderungen der Struktur, die unterdessen in der Wand des Ductus aufgetreten sind. Schon am Ende des 2. Lebenstages findet man die bereits in der Mitte in Wucherung begriffenen longitudinalen Schichten der Media in der Nähe der Intima entschieden vermehrt und ihre spindelförmigen Zellen in einer lebhaften Kerntheilung begriffen. Ferner treten auch zu gleicher Zeit Wucherungsprocesse auf der Innenfläche der Intima hervor. Ueber den Antheil der Blutgerinnung an der Obliteration ist Walk hoff der Ansicht, dass sich der Blutstrom an den rauhen Wänden bricht und auf diese Weise schnell zu Fibrinablagerungen Anlass giebt.

Hier hat Walkhoff genau beschrieben, wie der definitive Verschluss des Ductus arteriosus durch Wucherung der Bestandtheile seiner Wandung hervorgerufen wird, aber er hat auch ausgesprochen, dass eine Knickung des Ganges beim Einsetzen der Athmung eintritt, und dass "durch Ausdehnung der hinteren Wand der Theilungsstelle der Art. pulmonalis sein Anheftungspunkt so an deren vordere Wand gedrängt wird, dass ein von innen wirkender Druck seine untere Wand ventilartig gegen die obere andriicken muss." Er spricht also hier aus, dass ausser dem Verschluss durch Gewebsneubildung schon ein Verschluss durch mechanische Momente hervorgerufen wird, und dieser muss eintreten mit dem Beginn der Respiration; dies letztere hat er nach meiner Ansicht nicht genügend hervorgehoben, und dies ist von bedeutender Wichtigkeit für die Cirkulationsänderungen bei der Geburt. Ich weiche in meiner Ansicht über die Art des mechanischen Verschlusses wesentlich von Walkhoff ab, möchte aber schon hier hervorheben, dass es für die Beurtheilung der Kreislaufsänderungen bei der Geburt zunächst nur darauf ankommt, dass mit dem Einsetzen der Athmung Bedingungen geschaffen werden, welche den Ductus arteriosus zum Verschluss bringen.

Im Jahre 1871 erschien dann das Werk meines hochverehrten Lehrers Prof. S. B. Schultze, Der Scheintod Neugeborner, in dem er ausführlich auf den Verschluss des Ductus arteriosus und die Cirkulationsänderungen bei der Geburt eingeht. Er schildert (Seite 92 u. folgende) den Vorgang folgendermaassen:

Der Ductus Botalli besitzt nicht, wie das Foramen orale, eine Klappe, welche je höher der Druck auf Seite der Klappe steigt, um so fester das Lumen verschliesst, er obliterirt, nachdem er 
bis dahin ein nach beiden Seiten offenes Arterienrohr darstellte. Wir seben zuvor offene Arterienrohre obliteriren, entweder wenn, ohne Herabsetzung des Blutdrucks, die Blutsäule in Stillstand versetzt wird, so z. B. nach der Unterbindung; die Obliteration findet dann nach vorausgegangener Thrombenbildung statt; oder wenn durch tiefes Sinken des Blutdruckes die sich contrahirende Gefässwand das Uebergewicht über die noch nicht coagulirte Blutsäule gewinnt und dieselbe allmählich verdrängt, wie z. B. an den auch nicht unterbundenen Nabelarterien, wo dann die Obliteration ohne oder nur mit geringer Thrombusbildung erfolgt. Wenn tiefes Sinken des Blutdruckes mit Stagnation der Blutsäule zusammenfällt, werden die Bedingungen für die Obliteration ohne erhebliche Thrombenbildung am. giunstigsten sein. Das ist der Fall beim Ductus Botalli. Stillstand der Blutsäule im Duetus tritt ein zu der Zeit, wo die Druckdifferenz zwischen Pulmonalis und Aorta descendens gleich Null ist, und aus obiger Erörterung geht hervor, dass diese Periode des Stillstandes der Blutsäule im Ductus normaler Weise in die Zeit beiderseits tief herabgesetzten Druckes fällt. In der ganzen Periode tief herabgesetzten Druckes kann die Druckdifferenz zwischen Pulmonalis und Aorta und also auch die Strömung im Ductus nur eine geringe sein, denn auf der Pulmonalisseite, wo früher der höhere Druck war, fand die stärkere Herabsetzung des Druckes statt. Diese ganze Periode ist also für Verengung des Ductus guinstig und sie dauert jedenfalls Stunden, vielleicht Tage lang, denn die Herabsetzung des Druckes in der Pulmonalis bleibt permanent, das allmähliche Steigen des Druckes in der Aorta gelit mit der Hypertrophie des linken Ventrikels gleichen Schritt. Jedenfalls tritt nun, bevor der Aortendruck den der Pulmonalis tibersteigt, ein Stadinm ein, in welchem er ihm gleich kommt, in welchem also bei tief gesunkenem Druck alle Strömung im Ductus aufhört. Das ist der Zeitpunkt für vollständige Verschliessung des Ductus. Die genannte Periode ist der Schliessung des Ductus um so günstiger, wenn, wie sehr wahrscheinlich, aber meines Wissens durch anatomische Untersuchung nicht nachgewiesen ist, in der Wand des Ductus am reifen Fötus die contraktilen Elemente über die elastischen, anders als in anderen Arterien, das Uebergewicht haben."

Dass diese Erklärung nicht zutreffend ist, wird sich ergeben, wenn man das Schema (Fig. 1) betrachtet. Es fliesst das 
Blut in der Richtung der eingezeichneten Pfeile. Ist da denkbar, dass das Blut im Ductus arteriosus stillstehen kann? Muss nicht von der Pulmonalarterie her mit jeder Systole ein gewisser Blutstrom gegen die Blutsäule des Ductus stossen? Muss nicht die Aorta aus dem Ductus Blut mit sich fortreissen? Ja, muss nicht schon bloss eine Bewegung des ganzen Körpers das Gleichgewicht stören? Aber selbst wenn man keinen von diesen Punkten gelten lassen will, lässt sich noch ein Moment dagegen anführen. Bei der Respiration treten doch sicher Druckschwankungen in der Art. pulmonalis ein, seien diese nun bei der Inspiration Erhöhung, bei der Exspiration Herabsetzung des Blutdruckes oder umgekehrt, dies ist gleichgültig, ebenso treten Schwankungen im Aortengebiet auf, die durch die Respiration hervorgerufen werden. Diese Druckschwankungen in der Art. pulmonalis werden wohl eher auftreten als die Druckschwankungen in der Aorta an der Einmündungsstelle des Ductus; schon hierdurch müsste eine Strömung entstehen, und zwar erst recht, wenn die Druckänderungen an den beiden Stellen, was mir wahrscheinlich ist, einander eutgegengesetzt sind.

In dem dann folgenden Abschnitt sucht Schultze die Möglichkeit aufzustellen, dass die von Langer und Walkhoff geschilderten Spindelzellen, die diese ausdrücklich nicht für glatte Muskelzellen halten können, doch solche sind. Ferner giebt er zu, dass man der Richtungsänderung des Ductus, wie sie Walk bof $f$ geschildert hat, doch einige Bedeutung beimessen muss. Ja, er kommt zu dem Schluss, dass ein mechanischer Verschluss des Ductus bis zur vollendeten Gewebsobliteration nothwendig stattfinden muss, denn Seite 94 heisst es :

„Die vollständige Obliteration des Ductus, welche durch Gewebsneubildung erfolgt, kann beim Ductus, wie auch beim Foramen ovale erst das Werk von Wochen sein, and da das für die Obliteration günstigste Stadium gleichen Druckes diesseit und jenseit des Ductus nicht lange dauern kann, da normal jedenfalls schon nach Tagen, oft vielleicht nach Stunden extrauterinen Lebens der Aortendruck den der Pulmonalis tabersteigt, da sehr oft ohne Zweifel gerade in den ersten Lebenstagen Bedingungen existiren, die den Druck in der Pulmonalis höher als normal erhalten (Atelectase, jedes Hinderniss für die capilläre Lungencirkulation), in welchen Fällen das Stadium der Druckgleichheit beiderseits vom Ductus später und in eine Periode höheren Druckes fällt, da an- 
dererseits Bedingungen, welche den Aortendruck schneller als normal steigen lassen (vermehrte Widerstände im Körpercapillargebiet) ebenfalls sehr häufig sind, in welchen Fällen das Stadium der Druckgleichheit ein sehr schnell vorübergehendes ist: so $\mathrm{w}$ ü $\mathrm{r}$ de ohne Existenzirgendeines inzwischen eintretenden mechanischen Verschlusses es sich je. denfalls oft ereignen müssen, dass der Ductus dem von der Aorta her ausgeübten Ueberdruck wieder weichen undeiner in umgekehrter Richtung, alsesim Fötus geschah, sichbewegenden Bluts äuleden Durchgang gestatten müsste. Un. mittelbar tödtlich würde das nicht nothwendig, also nachweisbar in älteren Leichen sein, und die Seltenheit des Offenbleibens des Ductus iiber die ersten Wochen hinaus ist gerade anatomisch nachgewiesen. Also mussein me chan is cher Verschlus des Ductus bis zur vollendeten Gewebsobliteration nothwendig stat finden. Man muisste entweder eine förmliche Knickung des Ductus durch die ersten Respirationen annehmen, die den Weg verlegt, oder es existirt eine besonders stark entwickelte Ringmuskulatur. Man findet nicht nur bei kurz nach der Geburt gestorbenen, sondern auch bei ohne Luftathmung in utero gestorbenen Kindern, bei denen ja ganz ähnliche Cirkulationsänderungen wie normal nach der Geburt zu Stande kommen, zuweilen die Tunica intima des Ductus gerunzelt und gebrochen, wie die einer frisch unterbundenen Arterie. Dieser Befund, ferner die exquisite Längsfaltung der Intima und die sanduhrförmige Gestalt des Lumens am obliterirenden Ductus möchte sich leichter aus einer ringförmigen Constriktion als aus einer Knickung des Ductus erklären. Der anatomische Nachweis wird entscheiden, welches der mechanische Verschluss ist, der den Ductus Botalli trifft."

Bei der Vergleichung aller der in der Literatur niedergelegten Ansichten über den Verschluss des Ductus arteriosus findet man, dass fast alle Forscher zu dem Schluss kommen, dass ausser dem definitiven Verschluss durch Gewebsneubildung ein mechanischer Verschluss desselben statthaben muss, wenn auch über die Art, wie derselbe zu Stande kommt, die Meinungen noch wesentlich abweichen.

Eige nes: Ist man aber der Ansicht, dass der Ductus arteriosus, 
bevor er durch Gewebsneubildung zum Verschluss kommt, durch ein mechanisches Moment verschlossen wird, so wird man fragen, wann tritt dieser mechanische Verschluss ein. Vor der Geburt in utero kann er nicht eintreten, ohne das Leben des Kindes zu gefährden. Mit der ersten Inspiration treten im Thorax die verschiedensten Veränderungen anf, alle Durchmesser desselben werden mit einem Mal geändert. Bei dem weiteren Athmen bilden sich wieder gegen einander stabile Verhältnisse im Brustkorb aus, alle Organe, die mit der Erweiterung des Thorax ihre gegenseítige Lage verändert hatten, treten mit der Zeit in ein festes gegenseitiges Verhältniss, und es ist wohl nicht möglich, dass wenn dieses Verbältniss schon hergestellt ist, noch ein mechanisches Moment eintreten könnte, welches den Verschluss des Ductus arteriosus bedingte. Die Zeit, in welcher durch mechanische Momente der Ductus geschlossen werden kann, muss darum wohl in die Zeit der ersten Respirationen fallen. Betrachten wir daher einmal die Lage der Brusteingeweide vor der ersten Respiration und dann dieselbe nach derselben.

Beim Kind, das noch nicht geathmet hat, ist der Thorax nach allen Richtungen hin kleiner als bei dem, das schon geathmet hat, das Zwerchfell steht hoch, die atelectatischen Lungen liegen zu beiden Seiten der Wirbelsäule an, das Herz liegt ziemlich horizontal und reicht nach hinten bis an die Wirbelsäule, der Aortenbogen verläuft nicht von vorn nach hinten, sondern mehr quer von rechts nach links. Das Ende des Aortenbogens berührt die Wirbelsäule und ist an diese theils durch Bindegewebsmassen, theils durch die zablreichen Interkostalarterien befestigt. Gegenüber der Stelle, wo der Aortenbogen die Wirbelsäule berührt und an sie fixirt ist, mündet der Ductus arteriosus. An seinem Ursprung gehen die Pulmonalarterienäste ab. An der Abgangsstelle derselben ist die Umschlagsstelle des Pericards. Dies letztere steht in festem Zusammenhang mit dem Mediastinum und dureb dieses mit dem Sternum, ebenso ist das Perikard fest mit dem Zwerchfell verbunden.

Beim Kind, das schon geathmet hat, hat sich der Thorax ausgedehnt, die Rippen und mit ihnen das Sternum hat sich gehoben, das Zwerchfell hat sich gesenkt, das Herz hat sich von der Wirbelsäule entfernt und infolge des Tiefertritts des Zwerchfells auch gesenkt, die Lunge hat sich um ein vielfaches ihres Volu- 
mens vergrössert, der Lungenhilus, der erst an der Wirbelsäule lag, hat sich von dieser entfernt und ist in die Mitte des Brustkorbes geriickt. Welchen Einfluss muss diese Veränderung der Nachbarorgane auf den Ductus arteriosus haben? (Vergleiche Figur IV.) Derselbe mündet in die Aorta an einer Stelle, wo diese durch Bindegewebsmassen und durch die abgehenden Arterien an der Wirbelsäule befestigt ist, also ist auch das eine Ende des Ductus arteriosus, die Einmündungsstelle in die Aorta, fixirt. Am anderen Ende desselben entspringen die Pulmonalarterienäste und an derselben Stelle befindet sich die Umschlagsstelle des Perikards auf die Arteria pulmonalis. Wird von hier aus ein Zug auf den Ductus ausgeïbt, so kann dieses Ende dem Zug mehr oder weniger folgen. Welche von den eben geschilderten Veränderungen im Thorax werden aber auf das freie Ende des Ductns einwirken können?

1) Der Hilus der atelektatischen Lunge liegt an der Wirbelsäule an, bei der Inspiration entfernt er sich von derselben, er riickt mehr nach der Mitte des Thorax. Im Lungenhilus munden die Lungenarterien, sie werden auch dieser Verlagerung des Hilus folgen und sich von der Wirbelsäule entfernen müssen. Sie stehen mit dem freien Ende des Ductus arteriosus in Verbindung, dasselbe muss den Bewegungen der Pulmonalarterien folgen; das eine Ende ist fixirt, die Verschiebung des anderen muss eine Lageveränderung des Ductus hervorrufen, die wesentlich darin besteht, dass der Winkel an der Einmündungsstelle verändert wird. Aber auch der Winkel, den der Stamm den Pulmonalarterien mit dem.Ductus bildet, hat sich dadurch geändert. Aber diese Veränderung kann so éinfach nur sein, wenn der Abstand der Ursprünge der Pulmonalarterien von der Wirbelsäule nicht grösser geworden ist, als die Länge des Ductus beträgt; wird dieser $A b$ stand grösser, so muss auch von den Lungenarterienästen ein Zug des Ductus in die Länge hervorgerufen werden.

2) An dem freien Ende des Ductus arteriosus befindet sich die Umschlagsstelle des Perikards, dasselbe steht in fester Verbindung mit dem Zwerchfell, durch den Tiefertritt desselben muss auch das Herz tiefer treten, da dies durch das Perikard an jenes befestigt ist, aber hierdurch muss auch ein Zug an der Umschlagsstelle des Perikards an der Arteria pulmonalis ausgeübt werden, dieser Zng wird sich weiter erstrecken auf den Ductus, da dieser 
aber an seinem Aortenende fixirt ist, so wird sich dieser Zug äussern als eine Zerrung des Ganges. Am stärksten wird diese sein auf der Höhe der Inspiration.

3) Das Perikard steht aber ferner noch in fester Verbindung mit dem Sternum durch das Mediastinum. Wenn der Abstand zwischen der Wirbelsäule und dem Sternum grösser wird, so wird sich auch vom Sternum aus ein $\mathrm{Zug}$ auf das Perikard fortpflanzen bis zur Umschlagsstelle desselben auf die Arteria pulmonalis, der sich auch als eine Zerrung des Ductus arteriosus äussern wird.

Diese Behauptungen suche ich durch folgende Beobachtungen zu stützen:

Ad 1. Bei einem Kinde, das im 6. Monat der Schwangerschaft, ohne irgend welche Athembewegungen zu machen, während der Geburt abstarb, öffnete ich vorsichtig den Thorax und fand die oben geschilderten Verhältnisse. Ich band dem Kind eine Kanüle in die Trachea und blies die Lunge auf. Vor dem Aufblasen konnte man den Ductus arteriosus leicht in seiner ganzen Ausdehnung betrachten, man brauchte nur die auf ihm liegende atelektatische Lunge mit einem Instrument etwas zu lüften. Als die Lunge aufgeblasen wurde, sab man deutlich den Hilus derselben $1-11 / 2$ Finger breit nach vorn rücken. Von einer Zerrung des Ductus selbst konnte dabei natürlich nichts gesehen werden, die aufgeblähte Lunge hatte sich bis ziemlich zur Medianlinie tiber ihn verschoben. Ich habe die Lunge nicht nach der Seite vordrängen wollen, um den Gang zu sehen, weil ich befurchtete, dass, selbst wenn durch die Aufblähung keine Zerrung hervorgerufen worden wäre, hierdurch eine unnatürliche Zerrung hätte erzeugt worden können. Ich liess die Luft wieder ausstreichen, blies die Lunge von Neuem kräftig auf und setzte dies' eine geraume Zeit lang fort. Dann schnitt ich die Brusteingeweide vorsichtig heraus, schnitt in die Arteria pulmonalis ein, konnte mit der Scheere in den Ductus, der nach meinem Augenmaass gemessen auch verlängert war, leicht eingehen, ich schnitt ihn auf und fand auf seiner Innenfläche eine Anzahl Falten. Es wird wohl Niemand annehmen, dass diese Falten schon vorher existirt haben, sie miissen wohl in irgend einem Zusammenhang mit der Aufblähung der Lunge stehen. Uebrigens habe ich mir auch einen Ductus arteriosus von einem Kinde aus demselben (6.) Monat zu verschaffen gewusst, auf dessen Intima keine Falten zu sehen sind. 
Ad 2. Bei einigen ausgetragenen Kindern, die bei der Geburt abstarben, labe ich den Brustkorb auf der rechten Seite geöffnet, indem ich in demselben ein Fenster einschnitt, dieses musste jedoch so gelegt werden, dass das Sternum, vor allem der Ansatz des Mediastinums und das Zwerchfell mit dem Ansatz an die Rippen, ferner aber auch das Perikard unversehrt' blieb. Dieses Fenster wurde allmählich vergrössert dadurch, dass ich immer mehr von den Rippen abtrug. Dann versuchte ich den linken Lungenfligel nach und nach abzutragen; hatte ich diesen Stück fuir Stiick entfernt, so erhielt ich Einblick auf das Herz und die Brustgefässe. Nun öffnete ich die Bauchböhle, fasste die Leber mit einer Pincette und zog sie nach unten, schon bei kleinen Bewegungen konnte man sehen, dass sich das Perikard anzog, und dass sich dieser Zug bis zur Umschlagsstelle des Perikards fortpflanzte.

Ad 3. Noch bedeutender wurde dieser Zug, wenn man gleichzeitig auch das Sternum mit einer Pincette etwas anzog. Bedingung für das Gelingen dieses Versuches ist, dass das Mediastinum, das Zwerchfell mit dem Ansatz und vor allem das Perikard nicht verletzt ist. Der $\mathrm{Zug}$ am $\mathrm{Zwerehfell}$ uberschritt nicht die Grenzen der physiologischen Bewegung desselben.

Meine Ansicht ist nun folgende: das eine Ende des Ductus arteriosus, die Einmündugsstelle in die Aorta, ist fixirt, das andere Ende ist frei und kann einem an inm ausgetibten $\mathrm{Zug}$ bis zu einem gewissen Grad folgen. Ein solcher Zug kann ausgeübt werden durch die Palmonalarterien, welche an diesem Ende entspringen und durch das Perikard, welches sich hier umschlägt. Beim Einsetzen der Athmung machen die Lungenarterien eine Ortsbewegung, sie heben sich mit dem Lungenhilus von der Wirbelsäule ab und rucken in die Mitte des Thorax; durch den Tiefertritt des $\mathrm{Z}$ werch. fells erfährt das Perikard einen Zug nach unten und dadurch, dass sich das Sternum hebt, auch einen nach vorn, beide planzen sich fort bis auf die Umschlagsstellen desselben. Durch das Zusammenwirkendieser drei Faktoren wird sowohl die Richtung des Ductus arteriosus geändert, als auch eine Zerrung desselben bewirkt, die einen mechanischen Verschluss seines Lu- 
mens hervorruft. Diese mechanischen Einflisse der Respiration auf den Ductus arteriosus dürften kaum zu bestreiten sein, beim Einsetzen der Athmung werden alle Durchmesser des Thorax vergrössert. Organe, welche, wenn auch mittelbar, an der hinteren und vorderen Thoraxwand befestigt sind, muissen den Abstand ihrer fixen Punkte vergrössern. Der Aortenbogen, der im nicht erweiterten Thorax ziemlich quer von rechts nach links verläuft, richtet sich im erweiterten Thorax auf und verläuft mehr von vorn nach hinten. Der Ductus arteriosus aber liegt ziemlich in der Richtung des Zuges, in der sich der Thorax erweitert und muss gezerrt werden.

Worin äussert sich nun diese Zerrung dès Ductus arteriosus? Oben in dem ersten von mir angefuhrten Experimente fand ich bei einem sechsmonatlichen Föt, nachdem ich die Lungen oft und kräftig aufgeblasen hatte, den Ductus auf der Innenseite mit einer Anzahl Falten bedeckt. Bei einem anderen Föt ans demselben Monat, bei dem keine derartigen Versuche gemacht worden waren, war die Innenfläche des Ductus glatt. Bei einem ausgetragenen Kind, das an Nabelschnurvorfall in utero abgestorben war, zeigte der Ductus sehr zahlreiche und deutlich ausgeprägte Querfalten. Dasselbe fand ich beim Ductus arteriosus von zwei Kindern, die mittelst Cephalotripsie geboren worden waren. B. Schultze sagt: "Man findet nicht nur bei kurz nach der Geburt gestorbenen, sondern auch bei ohne Luftathmung in utero gestorbenen Kindern, bei denen ja durch vorzeitige Athembewegungen ganz ähnliche Cirkulationsänderungen wie normal nach der Geburt zu Stande kommen, zuweilen die Tunica intima gerunzelt und gebrochen, wie die einer frisch unterbundenen Arterie."

Lässt sich dieser Befund irgend wie durch die Zerrung des Ductus erklären? Die Wandung desselben besteht aus verschiedenen Schichten, zerre ich ihn, so werden die verschiedenen Schichten der Wandung dem Zug folgen müssen, lässt der Zug nach, so werden die elastischen Schichten ihre frühere Länge wieder einzunehmen suchen, die nicht elastischen können sich nicht zusammenziehen, da sie aber mit den elastischen verwachsen sind, so werden sie von diesen mit zusammengezogen, sie mussen sich aber dabei in Falten legen, die quer verlaufen. Untersucht man aber den Ductus arter. eines Kindes, welches 8-14 Tage gelebt hat, so ist das Bild ein ganz anderes. Der Ductus hat die 
Form einer Sandubr, von Querfalten ist nichts zu sehen, desto deutlicher sind aber die Längsfalten. Wie lässt sicb dies erklären? Wenn der Ductus, welcher an dem einen Ende fixirt ist, von dem anderen gezerrt wird, so verengt sich sein Lamen am meisten in der Mitte, am wenigsten an den Enden, so kommt die Sanduhrform zu Stande. Ist bei der Verengung vor allem eine der äusseren Schichten betheiligt, so werden sich die inneren in Falten legen, diese Falten verlaufen aber längs des Gefässes. Macht das Kind in utero oder gleich nach der Geburt eine Anzahl kräftiger Athemzüge, so wird der Ductus bei der Inspiration auch diese Form annehmen, stirbt es aber ab, so hört der Zug an dem einen Ende auf, und man findet nicht diesen, sondern den vorhergeschilderten Befund, die elastischen Schichten suchen in ihre Lage zurickzukehren und legen die nicht elastischen in Falten, die quer verlaufen. Lebt das Kind aber weiter, wirkt immer und immer wieder der Zug auf den Ductus, so wird sich allmählich sein Gefüge so lockern, dass auch die elastischen Schichten ihre Elasticität verlieren, die Sanduhrform und die Längsfalten bleiben nun auch bestehen, zumal da unterdess schon der Prozess der Gewebsobliteration begonnen hat.

Die bei der Sektion zu findenden Veränderungen: die Querfalten in den ersten Tagen, die Längsfalten in den späteren, die Sanduhrform des Lumens, scheinen doch mit Deutlichkeit dafür zu sprechen, dass auch am Lebenden auf den Ductus arteriosus dieselben Momente zu seinem Verschluss zusammenwirken, wie ich sie oben einzeln zur Anschauung zu bringen suchte.

Um mich genau tiber die Structur des Ductus zu unterrichten, habe ich dieselbe bei einem Kind, welches in utero an Nabelschnurvorfall gestorben war, und bei einem anderen, welches durch Cephalotripsie geboren worden war, mikroskopisch untersucht. "Vor allem kam es mir darauf an zu sehen, ob der Ductus arteriosus eine besonders stark entwickelte Ringmuskulatur besitzt, durch deren Contraktion ein Verschluss des Duetus hervorgerufen werden könnte. Langer und Walkhoff bestreiten die Existenz von glatten Muskelzellen und halten die spindelförmigen Zellen, die sie im Ductus finden, für , spindelförmige Zellen, die sich, wie in anderen bindegewebigen Organen, zu Bindegewebs- und elastischen Fasern umbilden. Mein Bemuihen war an Schnitten mittelst eines 
Härtungs- oder Färbemittels eine Differenzirung von glatten Muskelzellen und Spindelzellen zu erreichen. Auch über die Basalmembran der Iris besteht noch ein Streit, ob diese aus glatten Muskelzellen besteht oder nicht. Ich habe die verschiedenen Methoden, die dort angegeben und geprobt worden waren, auch auf den Ductus arteriosus anzuwenden gesucht. Ich habe keine deutliche Differenzirung erreicht. Auch Versuche mit Palladiumchlorïr und -chlorid haben nicht zum Ziele geführt. Bei Längsschnitten durch Gefässe findet man die Muskelzellen der Ringmuskulatur immer in einer bestimmten Anordnung, es stehen immer eime Anzahl Kerne in einer Richtung aneinander gereiht, die durch ein Maschennetz von anderen ähnlichen Reihen getrennt sind. Diese charakteristische Anordnung sollte mir als Charakteristicum für die glatten Muskelzellen gelten. Ich färbte die Schnitte mit Picrocarmin, mit diesem und Dahlia, mit Hämatoxylin und habe damit ganz brauchbare Präparate erhalten, die besten aber bekam ich, wenn ich die Schnitte mit Picrocarmin färbte, diese dann in Hämatoxylin brachte und kurze Zeit in Natr. bichrom. concent. legte. Das, was mir zuerst auffiel, war, dass sich in der Media des Ductus auf allen Schnitten ein Spalt zeigte, ich hatte vorher schon eine ganze Anzahl anderer Arterien, um die obigen Methoden zu prïfen, so gebärtet und geschnitten, aber dies nie bemerkt; bei einem zweiten Ductus, den ich desshalb mit grösster Vorsicht härtete und schnitt, fand ich denselben Spalt. Wenn ich auch zugebe, dass er im Leben nicht so ausgeprägt ist, so scheint hier doch sicher zwischen 2 Schichten nur eine lose Verbindung stattzuhaben. Dieser Spalt lief nicht ununterbrochen fort, sondern an einigen Stellen hatten sich noch Verbindungsbalken zwischen den getrennten Schichten erhalten. Figur VI stellt einen solchen Sehnitt dar. Man findet die Grenze des Schnittes nach dem Lumen zu uneben, gewellt, entsprechend den Querfalten. Die intermediäre Schicht ist im Vergleich zu anderen Arterien bedeutend verdickt, diese Schicht geht tiber in eine andere aus elastischem und fibrillärem Bindegewebe, deren Zellen parallel zur Längsaxe des Gefässes angeordnet sind. Hinter dieser Schicht folgt der Spalt, jenseits desselben ist eine Schicht, die ich für Ringmuskulatur halte, sie zeigt die charakteristische Anordnung der Zellen in getrennten Reihen. Auf diese folgt wieder eine parallel zum Verlauf des Gefässes angeordnete Schicht, die elastischen Charakter trägt, der zu Aeusserst 
eine Schicht von lockerem Bindegewebe, die Adventitia, folgt. Nach dieser Untersuchung kann ich das Vorhandensein einer Ringmuskulatur nicht bestreiten, aber dieselbe halte ich für viel zu schwach, um eine Contraktion des Ductus bis zu seinem Verschluss zu bewirken. Sie ist ganz bedeutend schwächer als z. B. in der Femoralarterie. Vergleichen wir meinen histologischen Befund mit dem der früheren Autoren. Kiwisch findet am Ductus mehrfache anatomische Eigenthümlichkeiten, die er, wie folgt schildert: „Seine Wandungen sind durchgehend beträchtlich dicker als die der anstossenden Arterien, seine Innenfläche zeigt ein eigenthümlich punktirtes Aussehen, sowie seine mittleren Schichten eine Art cavernöses, leicht verschiebbares Gewebe darbieten". Lang e r findet am Ductus die nahe der Intima gelegenen longitudinalen Kernstränge vermehrt und die ganze Wandung infolge der mächtigen Kernwucherungen bedeutend dicker als die der Aorta und Pulmonalarterie. Diese Wucherung ertheilt der Innenfläche des Ductus ein runzliches Ansehen. Elastisches Gewebe kommt nach seiner Ansicht nicht zur Entwicklung, an seiner Statt ist eine Art unfertiges Bindegewebe vorhanden. Walkhoff findet die Struktur der Intima des Ductus bedeutend lockerer als in den benachbarten Arterien, das elastische Gewebe ist bei Weitem hinter dem der letzteren zurückgeblieben, noch evidenter ist dieser Unterschied in der Media. Er will aber im Gegensatz zu Langer ein elastisches Fasernetz von den Nachbararterien auf den Ductus ïbergehen gesehen haben. Zwischen den-Maschen dieses Netzwerkes findet er aber Haufen von Zellen mit exquisit spindelförmigem Charakter, die er für Zellen hält, die sich, wie in anderen bindegewebigen Organen, zu Bindegewebs- und elastischen Fasern umbilden. Diese Beobachtungen scheinen in einigen Punkten mit den meinigen übereinzustimmen, in den anderen zu widersprechen. Bevor ich sie aber mit den meinigen in Vergleich setzen kann, muss ich hervorheben, dass Langer und Walkhoff den Prozess der Gewebsobliteration $\mathrm{zu}$ beobachten sich bemühten, sie untersuchen den Ductus am 3, 4., 5., 9., 13. Tage und noch später. Meine Untersuchungen sind gemacht an Kindern, die in utero abgestorben waren, nachdem sie nur eine beschränkte Anzahl Athemzïge gemacht hatten. Langer und Walk hoff finden die nahe der Intima gelegenen longitudinalen Kernstränge vermehrt, dasselbe finde ich; die intermediäre Schicht ist auch bei meinen Präparaten vom Ductus 
bedeutend dicker als bei denen von anderen Arterien. Ebenso sah ich wie Walkh off aus den benachbarten Arterien elastische Faserbündel in den Ductus arteriosus übergehen. Alle Beobachter fanden das Gefuge der Wandung gelockert, ich konnte es nur an einer Stelle finden, nämlich einwärts von einer Schicht, die ich für glatte Muskelzellen halte. Denkt man sich aber, dass der Ductus mehrere Tage immer und immer wieder gedehnt wird, so ist es klar, dass diese Lockerung des Gefüges immer ausgesprochner wird und sich auch auf die anderen Schichten erstreckt. In die Maschen dieses gelockerten Gewebes werden sich aber sogenannte cytogene Bindegewebstellen einlagern, es wird zur Proliferation derselben kommen und es wird sich ganz das Bild ergeben, welches Langer und Walkboff schildern. So wird die Lockerung des Gefüges durch die Zerrung der Anlass zur Gewebsobliteration des Ductus arteriosus.

Es erübrigt nun noch zu zeigen, in wie weit meine Ansicht iiber den mechanischen Verschluss von der Walk hoff's abweicht. Man vergleiche die meiner Arbeit beigegebenen Schemata. (Ich projecire Alles auf die Medianebene des Körpers.) Fig. 1 zeigt die Verhältnisse vor dem Beginn der Athmung, Fig. 2 nach dem Beginn der Respiration, wie ich sie mir nach der Schilderung Walk hoff's zurechtgelegt habe. Der Ductus hat sich an seinen Enden geknickt und bildet so für einen in der Richtung des Pfeiles wirkenden Drnck an der mit * bezeichneten Stelle eine Art Ventil, dadurch dass dieselbe an die obere Wand angedruickt wird. Gegen diese Ansicht spricht die von fast allen Forschern, auch von ihm beschriebene Sanduhrform des sich verschliessenden Ductus, ferner jene Querfalten in den ersten Tagen und Längsfalten in den späteren. Meine Ansicht, welche ich in Fig. 3 schematisirt habe, gibt die Erklärung für die Form des Ductus, für die Entstehung der Quer- und Längsfalten, sowie für die eigenthïmlichen Strukturverhältnisse der Wandung. Walkoff erwähnt ja auch einmal die Dehnung der Wandung (oben S. 243 unten), hat ihr aber gar keine Bedeutung beigemessen, während ich darauf das Hauptgewicht lege; für die Beurtheilung der physiologischen Bedeutung des mechanischen Verschlusses wird es gleich bleiben, ob man sich Walk off's oder meiner Ansicht anschliesst, aber die später zu schildernden pathologischen Erscheinungen lassen sich durch Walk of f's Ansicht nicht erklären, und darum stelle ich meine der seinigen so schroff gegenüber. 
Bevor ich aber die physiologische Bedeutung eines mechanischen Verschlusses des Ductus arteriosus weiter ausführe, möchte ich erst noch einen anderen wesentlichen Punkt besprechen, ich finde ihn sehr präcis ausgesprochen in dem Werke meines hochverehrten Lehrers Prof. W. Preyer, Die specielle Physiologie des Embryo. Seite 89 daselbst sagt er: „Die erste Ausdehnung der atelektatischen Lunge hat zur Folge ein reichlicheres Einströmen des Blutes der Pulmonalarterien durch Aspiration". Hierauf möchte ich etwas näher eingehen. Vor der ersten Inspiration befinden sich die Lungen unter demselben Druck wie der übrige Körper, mit der ersten Inspiration kommen sie unter einen geringen Druck, der Blutdruck in ihnen muss fallen. Dies lässt sich nicht bestreiten, aber ein zweites Moment wirkt noch auf den Lungenkreislauf, die Lunge wird ausgedehnt. Der geringere Druck wirkt von allen Seiten auf die Lungen, und construiren wir uns die Richtungslinien, in denen derselbe wirkt; die oberen Partien werden nach oben, die binteren nach hinten, die seitlichen nach der Seite, die vorderen nach vorn, die unteren nach unten gezogen. Die Richtungslinien für diesen Zug werden also radiär nach allen Richtungen von der Lungenwurzel ausgehen. In die Lungenwurzel treten die Gefässe ein, sie werden doch nach den verschiedenen Richtungen auch in die Länge gezggen werden. Ich will annehmen, die Gefässe werden um das Dreifache ihrer ursprünglichen Länge gedehnt, das Capillarnetz wird dann nicht bloss um das Dreifache, sondern um das Vielfache verlängert. Durcb diese Ausdehnung des Gefässbaumes werden die Widerstände im Lungenkreislauf bedeutend vergrössert. Dieser Vergrösserung der Widerstände wird nun zwar der negative Druck, der sich im Thorax ausbildet, entgegen wirken. Dieser kann übrigens nicht sehr bedeutend sein, denn bei Kindern, welche bis 8 Tage gelebt und normal geathmet haben, sinken bei Eröffnung der Pleurahöhle die Lungen nicht zusammen, sondern sie bleiben der Brustwand anliegen.

Wägen wir diese beiden Momente gegen einander ab, so wird man mir wohl zugeben, dass der intrathorakale Druck schon sehr bedeutend wirkt, wenn er die Gefässe nur so weit offen hält, als sie es waren, bevor sich die Lunge aufblähte. Ich will jedem anheimstellen, dem einen oder dem anderen Moment mehr oder weniger Bedeutung beizumessen, aber soviel steht fest, dass der Her- 
absetzung des Blutdruckes durch Aspiration ein bedeutender Faktor entgegenwirkt, nämlich die Erhöhung desselben durch die Vergrösserung des Gefässbaumes, und dass das Bild, welches ich irgendwo gefunden habe, die Lunge sauge das Blut an wie ein vorher ausgedriickter Schwamm, den Verhältnissen nicht entspricht. Um aber einen schlagenden Beweis zu erbringen, dass die Aspiration es nicht allein ist, durch die das reichlichere Einfliessen des. Blutes in die Pulmonalarterien veranlasst wird, sei es mir gestattet, schon jetzt ein klinisches Beispiel anzuführen, das gleichsam als physiologisches Experiment am Menschen betrachtet werden kann. Die Aspiration kann doch nur eintreten, wenn im Thorax ein negativer Druck erzengt wird. Sie kann nie zu Stande kommen, wenn derselbe gleich bleibt oder gar positiv gesteigert wird. Es ist eine allgemein bekannte und vielgeübte Wiederbelebungsmethode, scheintodten Neugeborenen mit einem Katheder Luft in die Trachea einzublasen und zwar so heftig, dass der 'Thorax durch positiven Druck erweitert wird. Hier kann doch sicher keine Aspiration eintreten, der Druck im Thorax ist positiv gesteigert und trotzdem kommt die Lungencirkulation zur Entwicklung, es werden viele scheintodte Kinder auf diese Weise belebt. Hieraus geht doch mit Deutlichkeit hervor, dass es nicht allein die Aspiration ist, durch welche die Lungencirkulation zur Entfaltung kommt, sondern dass auch andere Momente auf dieselbe einwirken müssen.

Ist man nach den Austührungen der oben angeführten Autoren und nach meiner Auseinandersetzung zu der Ueberzeugung gelangt, dass ein mechanischer Verschluss des Ductus vor der Gewebsobliteration vorhanden ist, so wird man auch der Ansicht sein, dass dieser durch das Einsetzen der Athmung hervorgerufen werden muss. Welchen Einfluss aber muss dieser mechanische Verschluss auf die Cirkulation beim Einsetzen der Athmung haben? Das rechte Herz wirft das Blut in den Truncus pulmonalis, das Blut kommt an den Ursprung des Ductus arter., dieser ist verschlossen, der Blutdruck in dem Truncus pulmonalis wird ausserordentlich steigen, das Blut wird mit aller Kraft in die Lungenarterien gepresst. Diese Steigerung des Blutdruckes wird es vor allem sein, die den Langenkreislauf zur Entfaltung bringt. Es liegt mir aber dabei fern alle anderen Momente, z. B. die Aspiration (der ich, wie oben ausgeführt, nicht die grosse Bedentung bei- 
messe, die man ihr allgemein zugeschrieben hat), vollständig auszuschliessen, nur wird sie, da sie mit dieser Drucksteigerung durch den Verschluss des Ductus zusammenfällt, die Entfaltung des Lungenkreislaufs noch begünstigen.

Durch den mechanischen Verschluss des Ductus arteriosus aber hat die Aorta descendens den Hauptzufluss eingebiisst, sie gehört jetzt ganz zum Stromgebiete des linken Ventrikels, das sich auf diese Weise fast verdoppelt, denn jetzt bat derselbe ausser der oberen Körperhälfte noch die ganze untere zu versorgen. Der Blutdruck im grossen Kreislauf muss rapid fallen. In den peripheren Gebieten schwindet der Puls, so auch in den Nabelarterien. Ich habe Alles hier geschildert, als geschehe es bei einer Respiration, ich habe es aber nur gethan, um es kurz und anschaulich zu schildern. Um den Ductus arter. so zu zerren, dass er sich schliesst, gehören sicher eine ganze Anzahl kräftiger Inspirationen. Je kräftiger das Kind athmet, desto eher wird er sich schliessen, desto eher wird der Nabelpuls erlöschen. Ich bin nämlich der Ansicht, dass der Ductus arter. geschlossen ist, wenn der Nabelpuls erlischt.

Vor dem Schluss des Ductus arter. ruhte auf dem linken Ventrikel fast nur die Blutsäule für die obere Körperhälfte, jetzt nach Schluss desselben wird diese Blutsänle doppelt so gross, diese kann nicht mehr durch dieselbe Kraft bewegt werden, wie vorher. Die Folge wird sein eine Staung des Blutes in den Arterien. Betrachtet man das Neugeborne in diesem Stadium, so zeigt sich diese Stauung schon in der Färbung der Haut, die unteren Extremitäten sind ziemlich blauroth, der übrige Körper zeigt eine rothe Farbe, aber nicht so bellroth, wie sie entsteht, wenn die Hauptkapillaren erweitert sind, sondern das Roth ist mehr gesattigt and zeigt eher einen Stich ins Blaue. Diese Staung erstreckt sich bis in das linke Herz, dasselbe ist insufficient, diese Blutmenge zu bewegen, es muss hypertrophiren. Dies entspricht auch den Erfahrungen am Krankenbett über die Entstehung der Hypertrophie des einen oder anderen Ventrikels. Diese Ansicht weicht insofern wesentlich von der ab, die Prof. B. Schultze im „Scheintod Neugeborener" p. 90 ausgesprochen hat, als ich nicht der Ansicht bin, dass durch die promptere und leichtere Füllung des linken Herzens im Vergleich zum rechten eine Blutdrucksteigerung im grossen Kreislauf hervorgerufen wird, die die Arbeit dem 
linken Ventrikel ersehwert und so zu dessen Hypertrophie führt, sondern dass die durch die Erweiterung des Stromgebietes vergrösserte Blutsäule dem linken Herzen die Arbeit erschwert und so zu seiner Hypertrophie Anlass wird.

Wie schon oben p. 241 angeführt, nimmt $\mathrm{Kiw}$ is ch an, dass eine Beziehung zwischen der Entfaltung der Lungenarterien und dem Verschluss des Ductus besteht, und glaubt, dass „eine eigenthümliche Nerventhätigkeit im Ductus eine ebenso lebhafte dem Blutandrang widerstehende Contraktion bewirkt, als antagonistisch eine gleichartige Relaxation in den Lungenarterien wirksam wird." Dass diese Beziehung existirt, aber nicht auf nervösen Einflïssen beruht, sondern auf rein mechanischen, wird aus Obigem klar. Ist die Respiration bei dem Neugebornen mangelhaft, so wird auch der Zug am freien Ende des Ductus schwach sein, derselbe wird sich vielleicht nur verengen, die Lungencirkulation wird sich nur mangelhaft entwickeln. Ist die Respiration anfangs kräftig, so wird sich der Ductus arter. verschliessen, wird dieselbe aber wieder aus irgend einem Grunde mangelhaft, so wird sich der Ductus leicht wieder eröffnen und den Blutstrom zum Theil wieder durchlassen, die Lungencirkulation wird dadurch leiden. Daraus ergeben sich klar die Beziehungen, wie sie $\mathrm{Kiwisch}$ schildert, welche zwischen den Athmungsexkursionen, dem Verschluss des Ductus und der Entfaltung der Lungencirkulation bestehen, je ausgiebiger die Athembewegungen, desto fester ist der Verschluss des Ductus, desto vollkommener ist die Lungencirkulation.

Nicht ganz unwesentlich für die Beurtheilung der Frage ob die Lungencirkulation lediglich durch Aspiration zu Stande kommt, oder ob der Blutstrom, welcher den Ductus arter. verschlossen findet, in die Pulmonalarterien gepresst wird und so zur Entfaltung des Lnngenkreislaufes führt, diirfte Fig. V sein. Sie ist nach einem Schnitt durch den Ductus art. eines Kaninchens vom 3. Tag gezeichnet. Der Schnitt liegt nicht ganz in der Längsaxe des Ductus, so kommt es, dass nach der Aorta zu das Lumen noch getroffen ist, während der Schnitt nach der Art. pulm. zu nur das sich versehliessende Lumen streift. Die Art. pulm. zeigt an den Stellen, wo sich ein * befindet, eine Vorwölbung, die man auch schon makroskopisch erkennen konnte. Diese lässt sich doch bloss erklären, wenn man annimmt, dass das Blut hier gegen die Wand anströmt, aber ein Hinderniss findet. Würde das Blut in der Rich- 
tung des Pfeiles nach der Lunge zu angesogen, so würde nie eine derartige Vorwölbung entstehen können.

Klinisch-pathologisches. Klinische und pathologische Erscheinungen, die durch diese Cirkulationsänderungen hervorgerufen werden, und die wiederum fiur den mechanischen Verschluss des Ductus arteriosus als Beweis dienen können, will ich noch zum Schluss meiner Arbeit besprechen. Nach einer Arbeit von Dr. Zi e g enspeck, in deren 3. Theil er die Pulsfrequenz beim Fötus und Neugeborenen einer Betrachtung unterzieht, findet sich kurz nach der Geburt als Begleiterin der ersten Athemziuge eine ganz enorme Pulssteigerung, wie sie im ganzen Leben nie wieder vorkommt, nach 15-20 Minuten sinkt sie zur Norm wieder herab. Auch $\mathrm{Zi}$ egenspeck glaubt, dass diese Erscheinung in irgend einem Zusammenhang mit dem Einströmen des Blutes in die neueröffnete Lungenbahn steht. Diese enorme Pulsbeschleunigung - ich will keine Theorie aufstellen über deren Ursache - und der dann folgende rasche Abfall sind doch sicher Beweise dafür, dass in dieser Zeit in der Cirkulation sich etwas abspielt, was beim Beginn des Abfalles beendet ist, ich glaube, dass dies nichts Anderes sein kann, als der Verschluss des Ductus arteriosus.

Beobachtet man den Nabelschnurpuls in der Zeit der ersten Athemzüge, so merkt man bei Beginn jeder Inspiration denselben schwinden. Dies erklärt sich nur dadurch, dass eben der Ductus arteriosus bei der Inspiration geschlossen wird, bei der Exspiration kehrt der Puls wieder, jetzt ist eben der Zug am Ductus so gering und die Elasticität des Ductus noch so stark, dass der Blutdruck von der Art. pulmonalis her ihn wieder eröffnet. Dieses Spiel setzt sich eine Zeitlang fort, bis das Gefüge des Ductus soweit gelockert ist, dass es seine Elasticität verliert, und derselbe auch bei der Exspiration durch den von dem erweiterten Thorax verursachten Zug geschlossen gehalten wird.

Zur Wiederbelebung asphyktischer Kinder haben sich seit langen Jahren die Schultze'schen Schwingungen als das erfolgreichste Mittel bewährt und, soviel ich weiss, nach vielen Anfechtungen therall eingebürgert. Prof. S. B. Schultze glaubt die Wirksamkeit derselben darin zu finden, dass durch dieselben die Ventilation der Lunge am ausgiebigsten bewirkt, die Cirkulation am meisten angeregt wird. Ich sehe ihren wesentlichen Einfluss auf die Cirkulation darin, dass sie den Verschluss des Ductus arteriosus bewirken. 
Durch das Ausschlagen des Kindes wird das Zwerchfell kräftig nach unten gerissen, dadurch entsteht der Zug am Ductus, der ihn verschliesst, jetzt steigt der Blutdruck in der Art. pulmonalis bedeutend, das Blut wird kräftig in die stark aufgeblähte Lunge getrieben, nun entwickclt sich ein vollkommener Lungenkreislauf, der zur Wiederbelebung des Nengeborenen führt.

Als Prof. B. S. Schultze dieses Semester in seiner Klinik diese Schwingungen demonstrirte, erzählte er einen für mich höchst interessanten Fall, den ich mir nach der Klinik möglichst wortgetreu notirte. Er sagte: „Ich wurde von einem Collegen, der verreisen musste, gebeten noch einmal ein Kind zu besuchen, das wohl noch an dem Tage sterben werde. Es sei acht Tage alt, die Respiration sei bei ihm immer mangelhaft gewesen. Ich besuchte das Kind, es war asphyktisch. Ich machte diese Schwingungen, und das Kind erholte sich zusehends." Die Athmung war bei diesem Kinde im Gange, freilich mangelhaft, aber dies bätte doch hinreichen muissen das Blut nach den Lungen zu aspiriren und die Lungencirkulation in Stand zu setzen. Bei diesem Kinde aber hatte sich wahrscheinlich die Lungencirkulation nicht entfaltet, erst durch die Schultze'schen Schwingungen ist der Ductus arteriosus geschlossen worden, und durch die dadurch entstehende Blutdrucksteigerung ist das Blut in die Lungen getrieben worden, dadurch hat sich erst die Lungeneirkulation entfaltet.

Einen noch interessanteren Fall erzählte er mir selbst, als ich ihm diese Ansicht auseinandersetzte: „Es kommt vor, dass ein Kind anfangs ganz gut athmet, die Athmung wird aus irgend einem Grunde wieder sehlecht und am vierten, fünften Tage tritt eine Nabelblutung ein." Dieser Fall erklärt sich sebr schön so: Bei Beginn der Athmung wurde der Ductus arteriosus geschlossen, als die Athmung schlecht wurde, verminderte sich der Zug von Seiten des Zwerchfells und der Pulmonalarterienäste an den Ductus, er konnte durch den Blutdruck von der Pulmonalarterie her wieder eröffnet werden. Die Folge war, dass der Blutdruck in der Aorta wieder stieg und Nabelblutungen eintraten. Das beste Mittel gegen diese Blutungen werden wieder die Schultze'schen Schwingungen sein.

Noch eins möchte ich über die Schultze'schen Schwingungen erwähnen. Meines Wissens hat man bei Kindern, welche noch weit von der Reife entfernt sind, nicht die glänzenden Erfolge wie mit 
reifen Kindern, ich glaube, man bezieht dies auf die grössere Weichheit des Brustkorbes; ich möchte noch auf etwas anderes hinweisen. Die Aorta ist an der Wirbelsäule durch bindegewebige Massen befestigt. Im 6. und 7. Monat ist aber diese Befestigung sebr leicht zu lösen, das Bindegewebe ist sebr locker. In denselben Monaten ist aber die Leber ein relativ sehr voluminöses Organ. Bei Kindern aus diesen Monaten werden die Schultze'schen Schwingungen beim kräftigen Ausschlagen den Effekt haben, dass dem Zug des Zwerchfells nicht nur der Ductus arteriosus folgt, sondern auch ein. Theil der Aorta. Dies braucht in der Aorta keine wesentliche Störungen hervorzubringen, aber es wird auch der Ductus nicht zum Verschluss gelangen und die Lungencirkulation nicht zu Stand kommen können (siehe Abbildung 9 und 10). Es würde sich daher aus rein theoretischen Erwägungen die Regel ergeben, bei den Schultze'schen Schwingungen mit frühgebornen Kindern nicht allzuheftig auszuschlagen, denn durch schwaches Ausschlagen kann der Ductus auch gezerrt werden, ohne ihn von seinem fixen Punkt loszureissen, und sollte diese Zerrung auch nur eine Verengerung hervorrufen, so lässt sich denken, dass, wenn sie gross genug ist, die dadurch entstandene Blutdrucksteigerung in der Art. pulmonalis hinreicht, um die Lungencirkulation zur Entfaltung zu bringen.

Intrauterine Athembewegungen werden zur Folge haben, dass der Blutdruck in den Nabelarterien mit einem Male tief sinkt. Mit der Exspiration wird er sich wieder ziemlich herstellen, mit einer neuen Inspiration aber wieder fallen, der Effekt wird sein die Asphyxie des Kindes. Welchen Sektionsbefund aber wird man in der Leiche der in diesem Stadium gestorbenen Kinder finden müssen? Bei der Inspiration wurde der Ductus geschlossen. das Blut mit verdoppelter Kraft vom rechten Ventrikel in die Lunge getrieben. Dies wird eine Blntfülle der Lunge bedingen, welche zuweilen zu Blutergïssen fïhren kann. Wäre dies denkbar, wenn die Lunge das Blut aspirirte? In der Lunge ist der Blutdruck gering, das Blat fliesst nach der Lunge und wird auch den Weg nach dem linken Ventrikel finden. Wie durch niedrigen Blutdruck Blutergüsse entstehen sollen, kann ich mir nicht denken, ebenso kann man doch bei der Sektion die Lungengefässe höchstens normal gefüllt aber nicht überfiillt finden. Prof. B. Scbultze futhrt aber ausdrücklich an, dass man bei in Asphyxie gestorbenen 
Kindern sehr bedeutende Blutfülle des rechten Herzens und der Lungengefässe constatiren kann, ebenso finden sich häufig subpleurale Blutergiisse. Seite 130 heisst es bei Schultze: "Was speciell die subserösen Extravasate betrifft, so hat schon $\mathrm{S} \mathrm{chwartz}$ mit Recht gegen Hecker erwähnt, dass dieselben mit weit mehr Wahrscheinlichkeit auf Staung in den Bronchialgefässen als auf Aspiration zu beziehen sind." Als Ursache dieser Blutextravasate unter die Pleura giebt Schultze die Rückstaung des Blutes durch Compression der Nabelarterien an. Darnach müsste die Unterbindung der Nabelschnur, bevor der Nabelpuls erloschen ist, erst recht denselben Effekt haben, das halte ich für unwahrscheinlich, Stauungserscheinungen durch Compression der Nabelarterien müssen vor allem im grossen Kreislauf und zwar zunächst in den Unterleibsorganen auftreten. Meine Ansicht ist, dass die subserösen Blutergüsse, die man an den Lungen der Kinder, die durch intrauterine Athembewegungen zu Grunde gegangen sind, findet, dadurch entstehen, dass das Blut, welches auf der Höhe der meist sehr angestrengten Inspiration den Ductus arteriosus schon ganz verschlossen findet, mit abnorm bohem Druck in die Lungengefässe gepresst wird, dieser hohe Druck ist die Ursache für die Blutextravasate. Das entgegengesetzte Bild bei der Sektion wird man bei Kindern finden müssen, die, ohne dass die Apnoe unterbrochen worden ist, durch Compression der Nabelschnur zu Grunde gegangen sind, bei diesen ist der Ductus arteriosus noch vollständig offen, aber ein grosser Theil des Stromgebietes der Aorta des- . cendens, die Nabelarterien, sind verschlossen, der Blutdruck in der Aorta muss ausserordentlich steigen, die Sektion wird ausserordentlichen Blatreichthum der Baucheingeweide constatiren müssen, ja selbst Blutergiisse können nach meiner Ansicht im Gebiete der Aorta descendens dadurch bervorgerufen werden. So deutlich werden sich nun freilich selten die Erscheinungen bei der Sektion trennen lassen, auch ehe bei Nabelschnurvorfall das Kind abstirbt, wird es Athembewegungen machen, und es werden sich dann beide Befunde vereinigt vorfinden.

Meiner Ansicht aber stehen scheinbar die, wenn auch seltenen Fälle gegenüber, bei denen der Ductus arteriosus noch im späteren Leben offen steht. Ich will zunächst citiren, wie Rokitansky die hierauf bezliglichen Präparate erklärt, die er in ,Ueber einige der wichtigsten Krankheiten der Arterien" beschreibt, da heisst es S. 35: 
„Die Form, unter welcher dies stattfindet, ist zweifach:

a) In den bei weitem häufigeren Fällen stellt der offen gebliebene Ductus ein trichterförmiges Gefässstiick dar, an welchem das Ostium aorticum weit, das Lungenarterienostium dagegen enge ist.

b) In seltenen Fällen ist es ein gleich weiter, kurzer, an beiden Ostien bis etwa auf die leistenförmige Begrenzung am vorderen Umfang des Ostiums aorticum gleichbeschaffener Canal.

Die Richtung des BIutstromes von der Aortanach der Lungenarterie ist in den ersten Fälen durch die Gestaltung des Canals und seiner Ostien unwiderleglich dargethan, $j a$ es hat das Lungenarterienostium zuweilen das Ansehen, dass man es als durch eine gewaltsame Wiedereröffu ug von der Aorta her gegeben halten möchte. Ueberdies spricht hierfür die fast in allen Fällen in der Volumszunahme des Gesammt-Herzens mehr oder weniger vorwiegende aktive Erweiterung des rechten Herzens. - Dieses macht wabrscheinlich, dass auch in dem 18. Falle (das Beispiel, welches er für die Fälle unter $b$ anführt) dieselbe Strömung von der Aorta nach der Lungenarterie statt hatte, wofür man weiteres noch die in der letzteren vorbandene Auflagerung beibringen könnte.

Als Grund des Offenbleibens des Ductus arteriosus kann nicht wohl ein oder das andere vereinzelte Moment, sondern ein Complex mehrerer, ja noch mehr ein rechtzeitiges Ineinandergreifen ihrer Wirksamkeit angesehen werden. Dem Ductus wohnt nämlich eine solche $\mathrm{Neigung}$ zur Involution inne, dass man ihn sehr gewöhnlich unter den ungünstigsten Bedingungen geschrumpft und verödet findet.

Ich kenne keinen Fall, in welchem die Involution des Ductus durch Hindernisse der Entwicklung des Lungenkreislaufes nach der Geburt hintangehalten und derselbe offen und zwar vom Lungenarterien-Ostium her offen geblieben wäre. In den seltenen Fällen, wo derselbe ungewöhnlich lange nach der Geburt eben noch und zwar gleichmässig durchgängig gefunden wurde, musste man dies vor der Hand wegen Mangels an Begründung ebenso wie das so häufige Offenbleiben des Foramen ovale in mässigem Grade für eine Zufälligkeit ansehen.

Meiner in den angeführten Beobachtungen bestehenden Erfahrung zufolge hat es den Anschein, als wenn der Ductus nur 
vom Ostium aorticum her zu einem persistenten Offenbleiben bestimmt werde, und ein hier in Betracht kommendes ursächliches Moment scheint mir die in derlei Fällen vorfindige Enge der Aorta, zumal wie gewöhnlich des Aortenbogens und der absteigenden Aorta zu sein. Tritt bei einer solchen eine rasche und ausgiebige Ablenkung des Blntstromes nach den Lungen ein, so wird sich das Aortenblut desto mehr nach und in den Ductus drängen, je ungenügender das Kaliber der Aorta ist. Dieser Strom wird je nach Umständen den Ductus gleichförmig oder aber, so ferne mit der Ablenkung des Lungenarterienstromes eine eben so rasche Involution des Ductus an seinem Lungenarterien-Ostium gegeben ist, denselben in der gewöhnlicheren conischen Form offen erhalten.

Und doch muss man gegenüber dieser begründeten Construirung des Faktums gestehen, dass der Ductus selbst bei monströser Enge der Aorta sich in der Regel in ganz gewöhnlicher Weise involvirt."

Hier sagt Rokitansky, blos ans der Betrachtung der pathologischen Präparate geschlossen, dass der Ductus arteriosus in den bei weitem hänfigsten Fällen vom Aortenostium her zu einem persistenten Offenbleiben bestimmt sei. Und das ist nach meiner Meinung das Wahrscheinliche, der Ductus war durch die ersten Athembewegungen verschlossen und blieb es während längerer Zeit, so dass die Lungencirkulation sich geniigend entfalten konnte. Der Aortendruck, der sich mit der Hypertrophie des linken Ventrikels hebt, wird in der trichterförmigen Ausstiilpung, die noch in der Aortenwandung an der Einmündungsstelle des Ductus vorhanden ist, einen Druck ausüben, der allmählich zur Erweiterung des Ductus fuibrt. Ebenso sind die Aneurysmen des Ductus arteriosus zu erklären. Sie haben alle das Charakteristische, dass sie nach der Aorta hin communiciren, während sie nach der Art. pulmonalis hin abgesehlossen sind. Es sind dies die Uebergänge zu dem Offenstehen des Ductus. Hier hat die Wiedereröffnung von der Aorta her erst stattgefunden, nachdem der Versehluss durch Gewebsneubildung an einer Stelle schon vollständig und fest war.

Aber selbst der Fall ist denkbar, dass der Ductus arteriosus beim Einsetzen der Athmung nicht ganz geschlossen wird. In solchen Fällen entsteht durch die Zerrung nur eine Verengerung des Ganges, die aher hinreicht, den Blutdruck in der Art. pulmonalis so zu steigern, dass sich die Lungencirkulation entwickeln kann. 
Ferner sagt Rokitansky, dass man bei abnormer Enge der Aorta das Offenstehen des Ductus arteriosus erwarten müsste, und dieser begründeten Construirung des Faktums gegenüber muss er doch eingestehen, „dass der Ductus selbst bei monströser Enge der Aorta sich in der Regel in ganz gewöhnlicher Weise involvirt". Daraus geht nach meiner Ansicht entschieden hervor, dass nicht blos aus Blutdruckschwankungen die Erklärung dieser merkwürdigen Thatsache gegeben werden kann, sondern dass noch ein anderer Faktor mitwirkt, den selbst bedeutende Steigerungen des Blutdruckes nicht überwinden können.

Wie liegen nun aber diese Verbältnisse bei Verengung des Stammes der Art. pulmonalis? Würde die Lungencirkulation durch die Aspiration der Lunge zu Stande kommen, so müsste man doch annehmen, wenn die Lunge nicht genügend Blut aus der Pulmonalarterie bekommen kann, sie würde es durch den Ductus aus der Aorta aspiriren; so könnte man sich einen Grund für das Offenstehen des Ductus construiren. Ich suchte mich darüber wieder bei Rokitansky zu orientiren. Dieser sagt: „Der Ductus Botalli ist neben Stenose und Atresie der Lungenarterie ungewöhnlich dünn und zarthäutig, er schrumpft auch ungewöhnlich frühzeitig und zwar a ugenfällig unter höchst ungünstigen Bedingungen." Auch bieraus glaube ich schiiessen zu können, dass die Involution des Ductus nicht von den Veränderungen des Blutdruckes im Stamme der Lungenarterie abhängig sei, sondern dass noch ein anderes Moment wirksam sein muss, welches nicht durch die Cirkulation selbst beeinflusst wird.

In demselben Werke von $\mathrm{Rok}$ i t a n s k y heisst es Seite 123: „Die Lungenarterie ist, jenseits der Stenose namentlich in ihren Aesten, zumal gegen den Lungenhilus hin weiter als das verengte Stiuck und zugleich mehr oder weniger a uffallend dinn und schlaffhäutig." Dies bringt mich auf die Vermuthung: könnte diese Stenose der Art. pulmonalis nicht auch durch diesen Vorgang, wie ich ihn oben geschildert habe, entstanden sein? Ist die Art. pulmonalis sehr zart gebaut, so wird der Zug von den Pulmonalarterienästen sehr gering sein, der Ductus wird vor allem durch den Zug des Pericarảs geschlossen werden, sollte aber durch diesen einseitigen Zug an der schwach angelegten Pulmonalarterie

1) Die Defecte der Scheidewände des Herzens. Wien 1875, S. 121. 
nicht eine Verengung derselben entstehen können. Es ist doch sicher sehr auffällig, dass Rokitansky gerade in diesen Fällen die Diinne und Schlaffheit der Arterienwandung hervorhebt, und die Beschreibung der Stelle der Verengung scheint mir genau der Umsehlagsstelle des Pericards zu entsprechen. Es dürfte für den, der darauf bezügliche Präparate zur Verfügung hat, lohnend sein, dieselben einmal darauf zu prüfen.

Ferner habe ich nach pathologischen Veränderungen gesucht, die durch die Zerrung unmittelbar hervorgerufen werden muissen. Ist z. B. die Aorta in der Höhe der Einmündungsstelle des Ductus noch nicht fest an der Wirbelsäule befestigt, so muss der Zug am Ductus dieselbe losreissen (siehe oben $\mathrm{S} .263$ über $\mathrm{S}$ c h u l t z e'sche Schwingungen) und eine winklige Einknickung derselben verursachen. Ich war geradezu iberrascht bei Rokitansky die beiden Abbildungen zu finden, die ich meiner Arbeit beigebe und die Alles besser illustriren, als ich es zu beschreiben im Stande bin. Auch Rokitansky bezieht diese Einknickung auf einen Zug, welcher bei der Obliteratur des Ductus an der Aorta ausgeiibt worden ist.

Auch die Fälle von Obliteration der Aorta an der Einmïndungsstelle des Ductus arteriosus können möglicher Weise durch den von mir geschilderten Vorgang ihre Erklärung finden.

\section{Erklärung der Abbildungen auf Tafel IV nnd V.}

Fig. I zeigt das Verbältniss des Ductus arteriosus zu den benachbarten Arterien vor der ersten Inspiration, die Pfeile zeigen die Richtung des Blutstromes. (Ich projicire Alles auf die Medianebene des Körpers.)

Fig. II zeigt den Verschluss, wie ich ihn nach der Schilderung Walkhoff's schematisirt habe. Der in der Richtung des Pfeiles wirkende Druck legt die mit einem Sternchen versehenen Ursprungsstellen der hinteren Wand des Ductus art. ventilartig an die vordere.

Fig. III zeigt den Verschluss, wie ich mir denselben denke. Die rothgezeichnete Linie b ist die Umschlagsstelle des Perikards, a soll die Fixation der Aorta an der Wirbelsärule, die theils durch Bindegewebsmassen, theils 
durch die abgehenden Interkostalarterien bewirkt wird, kennzeichnen; der Ductus ist verlängert und sanduhrförmig eingeschnürt.

Fig. IV zeigt die Brusteingeweide des ausgetragenen Kindes, a ist wieder die Fixationsstelle der Aorta, $\mathrm{b}$ ist die Umschlagsstelle des Perikards.

Fig. V sind die Umrisse eines Schnittes durch den Ductus art. eines 3 Tage alten Kaninchens, der Schnitt liegt nicht ganz in der Axe des Ductus art., sondern etwas schräg; nach der Pulmonalis zu berührt er gerade die vordere Wand, nach der Aorta zu trifft er noch dạs Lumen. Die mit einem Sternchen kezeichneten Ausbuchtungen weisen darauf hin, dass hier ein Druck von dem Stamm der Art. pulmonalis hin gegen den Ductus ausgeübt worden ist.

Fig. VI. Längsschnitt durch die Wandung des Ductus art. eines durch Nabelschnurvorfall in utero abgestorbenen Kindes. Die intermediäre Schicht ist bedeutend dicker als in anderen Arterien. Vor einer schwachentwickelten Muskelschicht findet sich ein Spalt, der aber an einer Stelle überbrückt ist.

Fig. VII. Ductus arteriosus von einem während der Geburt abgestorbenen, kräftig gebauten Kinde. a Aortenbogen, b Stamm der Pulmonalarterie, c Stelle, an der die Lungenarterien sich trennen, d Ductus arteriosus, e Aorta descendens. Die Innenfläche des Ductus zeigt zahlreiche Querrunzeln, am zahlreichsten an der vorderen Wandung, aber auch Längsfalten sind zu bemerken.

Fig. VIII. Ductus arteriosus von einem schwächlich gebauten Kinde, welches 3 Wochen gelebt hat. Der Stamm der Pulmonalarterie ist an der Theilungsstelle bei der Sektion abgesschnitten worden, f ist ein Theil der Art. pulm. dextr., der Ductus zeigt zahlreiche Längsfalten. Die Sanduhrform ist dadurch, dass der Zeichner sie stark auf der Fläche auszubreiten suchte, nicht recht deutlich dargestellt. Im Uebrigen die Bezeichnung wie bei Fig. VII.

Fig. IX u. X sind nach Rokitansky „Ueber einige der wichtigsten Krankheiten der Arterien" in: Denkschriften der kais. Academie der Wissenschaften. Math.-naturw. Klasse Wien 1852, Bd. 4 gezeichnet. Sie zeigen, dass die Aorta durch $\mathrm{Zug}$ vom Ductus arteriosus her von ihrer Befestigung an die Wirbelsäule losgerissen und winkelig eingeknickt werden kann. 


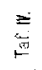
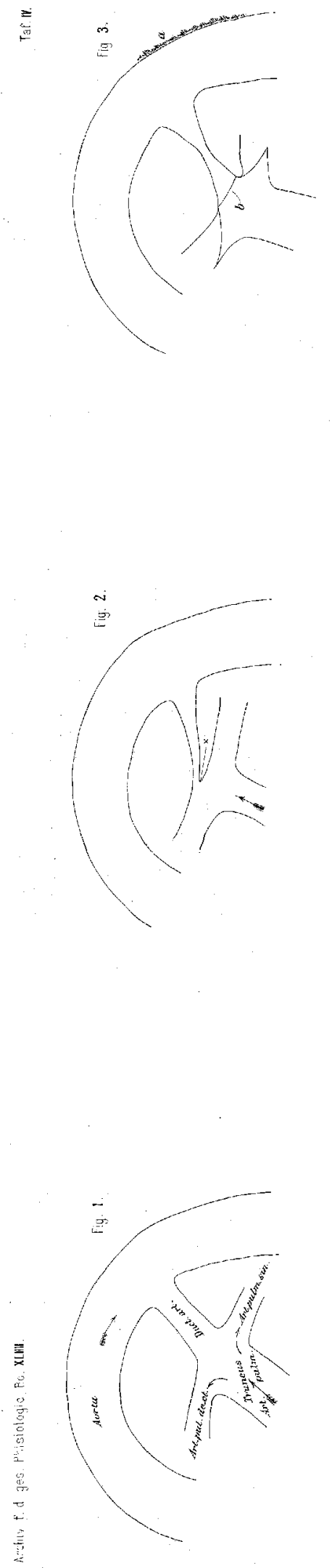
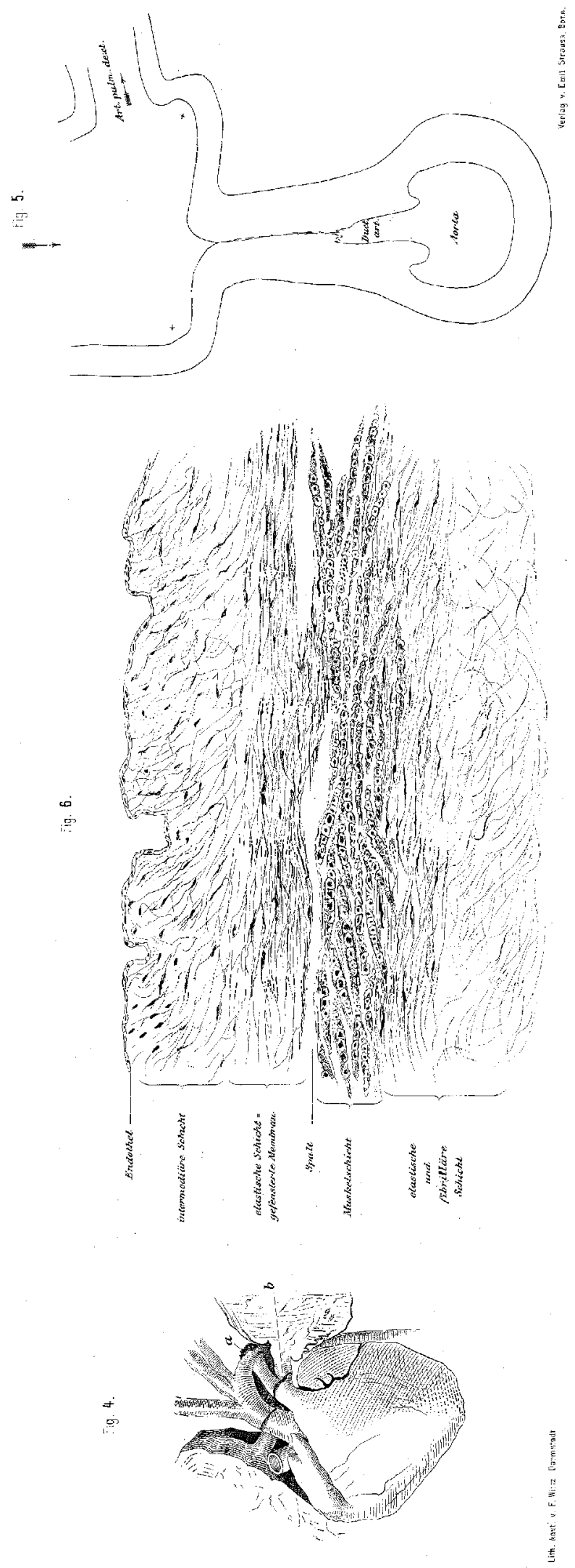
Archiv fid ges. Physiologie: Bd. XLIH. 
TaP $V$. 